\title{
Low physical activity is related to clustering of risk factors for fracture-a 2-year prospective study in children
}

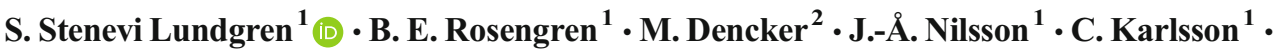 \\ M. K. Karlsson ${ }^{1}$
}

Received: 31 January 2017 / Accepted: 21 August 2017 /Published online: 15 September 2017

(C) The Author(s) 2017. This article is an open access publication

\begin{abstract}
Summary The study investigates the effect of physical activity (PA) on a composite score for fracture risk in pre-pubertal children. Low PA in children is related to the composite score for fracture risk and the pre-pubertal years seem to be a period when PA positively affects the score.

Introduction This study evaluates if PA in children is related to clustering of risk factors for fracture. Research questions are the following: (i) What is the effect of physical activity (PA) on single traits and a composite score for fracture risk? (ii) Could this score be used to identify the level of PA needed to reach beneficial effects?

Methods This prospective population-based study included 269 children, aged 7-9 years at baseline while 246 attended the 2-year follow-up. We estimated duration of PA by questionnaires and measured traits that independently predict fractures. We then calculated gender specific Z-scores for each variable. The mean Z-score of all traits was used as a composite score for fracture risk. We tested correlation between duration of PA, each trait, and the composite score and group differences between children in different quartiles of PA.

Results At baseline, we found no correlation between duration of PA and any of the traits or the composite score. At follow-up, we found a correlation between PA and the composite score. Physical activity had an effect on composite
\end{abstract}

S. Stenevi Lundgren

Susanna.SteneviLundgren@skane.se

1 Clinical and Molecular Osteoporosis Research Unit and Department of Clinical Sciences and Orthopedics, Lund University, Skane University Hospital, SE-205 02 Malmö, Sweden

2 Department of Clinical Physiology, Lund University, Skane University Hospital, SE-205 02 Malmö, Sweden score, and children in the lowest quartiles of PA had unbeneficial composite score compared to children in the other quartiles.

Conclusion Low PA in children is related to clustering of risk factors for fracture, and the pre-pubertal years seem to be a period when PA positively affects the composite score.

Keywords $\mathrm{BMC} \cdot$ Bonemineral content $\cdot$ Bonequality $\cdot$ Bone size $\cdot$ Boys $\cdot$ Children $\cdot$ Exercise $\cdot$ Fracture $\cdot$ Girls $\cdot$ Lean mass $\cdot$ Muscle strength $\cdot$ Neuromuscular function $\cdot$ Physical activity $\cdot$ Risk factors

\section{Introduction}

Osteoporosis is either the result of increased age-related bone loss [1] and/or insufficient bone accrual at growth [2]. Fracture prevention in old ages has mainly focused on pharmacological treatment [3] while life style changes have been advocated in young ages $[2,4]$. A high peak bone mass is also associated with low fracture risk [2, 5-9]. The most potent and modifiable lifestyle factor may be physical activity (PA) [10-16], especially if provided in the late pre- and early peri-pubertal period [14-16]. But bone strength is not only dependent bone mineral content (BMC) $[15,16]$. Bone-size, micro-, and macro-architectural structure and cortical porosity $[10,11$, $14,17]$ are traits that are independent of BMD associated with fracture risk $[10-12,14]$. And non-skeletal factors, such as muscle mass, muscle strength, balance, neuromuscular function, and coordination, are also of importance [11, 17-19].

The overall positive effect of PA could therefore be underestimated, if only using BMD as a surrogate end point for fracture [20, 21]. A composite score for fracture, including several risk factors that independently predict fracture, would probably better estimate fracture risk. Composite score has 
been used in cardiovascular research [22-26] and with FRAX when evaluating fracture risk in elderly [27]. No such studies have been done when estimating fracture risk in children. This is however important since early accumulation of risk factors is believed to have greater impact on fracture risk than a single-risk factor. The advantage with cluster analysis is also that it yields a comprehensive perspective on the effect of a studied intervention to reduce the risk of a disease (fracture) [22-26]. We hypothesized that a composite score would better estimate the effect of PA than using BMC (or BMD) alone. We asked the following: (i) What is the effect of PA on single traits and a composite score for fracture? (ii) Could this score be used to identify the level of PA needed to reach beneficial effects?

\section{Material and methods}

The pediatric osteoporosis prevention (POP) study is a population-based prospective controlled PA intervention study that has previously been reported in detail $[28,29]$. In summary, four neighboring, government-funded and community-based elementary schools were invited to participate. One school was chosen as intervention school and three as control schools. The intervention school PE from 60 to $200 \mathrm{~min} /$ week (40 min PE per school day) during the school term. The intervention was composed of ordinary PE lessons of moderate intensity level. The intervention was introduced shortly after the baseline measurement and continued throughout the study period. The control school continued with the Swedish standard curriculum. All activities were led by the same teachers as before study start. No other changes were done in the school curriculum.

We invited at baseline all the children in the first or second grade to participate. One hundred twenty-six out of 218 girls and 152/259 boys accepted to participate. We excluded two boys and one girl with medications that could affect the skeletal development and one girl as being 8 months younger than the others. The children were at study start $7.8 \pm 0.6$ years (mean $\pm \mathrm{SD}$ ) and $98 \%$ were of Caucasian ethnicity. Of the 124 girls and 150 boys included in the study, 119 girls and 150 boys attended the baseline measurement. At baseline, one girl had valid data from less than two variables and the baseline composite score was excluded. One hundred eight girls and 138 boys attended the re-measurement after 2 years. One hundred and thirteen girls and 145 boys answered the questionnaire regarding physical activity at baseline, and the corresponding figure at follow-up was 97 girls and 132 boys, respectively.

We collected at both baseline and follow-up anthropometric measurements of height $(\mathrm{cm})$ and weight $(\mathrm{kg})$ by standardized equipment (Holtain Stadiometer and Avery Berkel HL 120 electric scale). Body mass index (BMI) was calculated as weight $/$ height $^{2}$. A research nurse assessed Tanner stage [30] at baseline (all in Tanner 1) while self-assessment was used at the follow-up (four girls in Tanner 2). Life style (nutrition, alcohol, smoking, diseases, medications, weekly durations of school PA (physical educational (PE) classes), and durations of organized leisure-time PA in summer and winter) was evaluated by questionnaires [16]. We calculated the annual mean weekly duration of PA. Total PA was estimated as the sum of school PE and leisure-time PA.

We measured by dual-X-ray absorptiometry (DXA, DPXL ${ }^{\circledR}$ version 1.3z, Lunar Corporation, Madison, WI, USA) the bone mineral content (BMC, g) and bone area $\left(\mathrm{cm}^{2}\right)$ in the third lumbar vertebra; by quantitative ultrasound (QUS, Lunar Achilles model 1061®, Lunar Corporation, Madison, WI, USA) calcaneal broadband ultrasound attenuation (BUA, $\mathrm{dB} / \mathrm{MHz}$ ), being said to estimate also bone quality [31]; by vertical jump height (VJH) test neuromuscular function; and by a computerized dynamometer (Biodex System III Pro®) muscle strength as concentric isokinetic peak torque (PT) for right knee extension (ext) at a speed of $180^{\circ} / \mathrm{s}$. We used the highest PT value of ten repeated movements. All methods are described in detail in the previous publications [11, 16, 29]. Our research technicians performed all measurements and daily calibrated the DXA apparatus with a phantom. There was no long-term drift in the equipment. The coefficient of variation $(\mathrm{CV} \%)$, evaluated by duplicate measurements in 13 healthy children was $1.4-5.2 \%$ for BMC, 1.5 and $6.7 \%$ for BUA, and 12.3 and $12.3 \%$ for $\mathrm{PT}_{\text {ext }}$.

Drop-out analysis, by using data from the grade-one compulsory school health examinations, found no statistically significant group differences in age, height, weight, or BMI when comparing children who participated in the study with those who did not $[28,29]$. Also, there were no statistical baseline differences on the variables included in the study, bone measures, muscle function, and physical activity, between the subjects who dropped out compared to those who completed the 2-year follow-up. For the children who did not attend either the baseline or the follow-up measurement, the composite score yielded from the measurement they did attend was not significantly different compared to the composite score for the children who attended both measurements. As the Z-score for each individual is calculated based on the mean and standard deviation of the cohort, the Z-scores might be affected by changes in the cohort. To make sure, the choice to include individuals attending only one measurement in the cohort did not skew the Z-scores for those individuals attending both measurements, an additional analysis was made. The analysis was made in order to evaluate if the composite score for this group differed when calculated based on all children (with both or only one measurement) compared to when based only on children attending both measurements. Then, the composite scores for the children attending both measurements were compared and no difference was recognized. 
We used IBM SPSS Statistics ${ }^{\circledR}$ version 23 for statistical calculations. Skewed variables (Baseline BUA and PT for boys and follow-up BUA in boys and BMC, area, BUA and PT in girls) were normalized by natural logarithm. Data are presented as means with standard deviations (SD) and means with $95 \%$ confidence intervals $(95 \% \mathrm{CI})$. We calculated gender specific Z-scores for each trait according to the formula ((the value of that specific individual-the gender specific mean value for the trait) / the SD for the trait). We used the mean of the Z-scores for BMC (third lumbar vertebrae), area (third lumbar vertebrae), BUA, VHJ, and PT as a composite score for fracture. The rational for including each trait in the composite score was that in publications, it has been shown to influence fracture risk and being influenced by activity [5-9, 18-20]. Also, we decided to include one measurement of each trait, since for example, DXA measurements in different anatomical regions within one individual are not independent on each other. A higher Z-score in the combined risk score would then hypothetically have a fracture preventive effect. But since there are no studies that have used this score to predict fractures, we could not transfer what for example, a 0.3 standard deviation (SD) benefit would correspond to reduced fracture incidence or a $-0.3 \mathrm{SD}$ decrease in increased fracture risk. We then used linear regression (Pearson correlation) to assess correlation between PA and each trait (adjusted for age and height (as an estimate of growth)) and composite score (adjusted for age and height). The correlations were analyzed crosssectionally at baseline and follow-up, respectively. We used a multilevel linear mixed model with unstructured covariance structure and fixed intercept only to examine the effect of PA on the Z-score for each trait and the composite score, adjusted for age and height. An additional analysis was made where an interaction term between PA and PA quartile was added to the model. Subjects were nested within schools. The assumptions of the models were checked with residuals analyses. Statistical significance was set at a level of $p<0.05$. This study is approved by the Lund University Ethics Committee (LU 45398, LU-368-99), registered as a clinical trial with registration identification ClinicalTrials.gov.NCT00633828, and carried out in accordance with the Declaration of Helsinki. Written informed consent was obtained from the parents or guardians of each child before study start.

\section{Results}

Gender specific data are presented in Table 1. At baseline, we found no correlation between PA and individual traits or the composite score (Table 2).

At follow-up, we found correlation between PA during the study period and the composite score $(r=0.18, p=0.01)$, but (except for BUA) no other correlations between PA and individual traits (Table 2).
The linear mixed model analysis revealed no significant effect of which school the children attended on composite score. However, PA had effect on composite score, BMC, and area (Table 3). Also, when adding the quartiles of physical activity to the model, the lower quartile (Q1) had a significantly lower result compared to Q2 $(p<0.001)$, Q3 $(p<0.001)$, and Q4 $(p<0.001)$, respectively, for composite score.

\section{Discussion}

Our study shows that PA enhances the gain in several traits that independently reduce the fracture risk, as being estimated by a composite score, and that the pre-pubertal years probably is an important period for future fracture risk, as the score could be influenced in this period by also moderate PA.

We have previously shown in the POP cohort that PA confers benefits in BMC $[16,17]$ and muscle strength $[17,29]$. These effects were however only found on group level while no participant specific correlations could be shown between PA and the gain in each trait $[16,17,29]$. That is, if only relating the effect of PA to single traits, we may have disregarded beneficial effects on the individual level. In contrast, the current study infers that with clustering of risk factors as end point, there is actually an individual correlation between PA and the composite score. Composite scores have been used as end point variable for the effect of PA in childhood on cardiovascular disease [22-26], but this is to our knowledge the first time a pediatric composite score has been used to evaluate the effect by PA on fracture.

With the composite score, we may now be able to explain the previously unexplained magnitude of fracture reduction by PA in the POP study [20, 21]. In the previous studies, we found that the school-based PA intervention program was accompanied by an annual reduction in fracture incidence by $50 \%$ reduction in fracture incidence ratio during the seventh and eighth year of the intervention [20,21]. The accompanying BMD benefit could however only explain $25 \%$ of the fracture reduction [11, $20,21,32]$. In the current study, we found a plausible explanation, as PA is associated with measurable fracture risk benefits beyond those rendered by BMD.

Hypothetically, a PA intervention program would provide the greatest benefit in children with the lowest voluntary chosen PA. However, we have not been able to show this in previous reports when using BMD alone as the surrogate end point for fracture risk $[16,17]$. This study could not pinpoint the most beneficial level of PA for the composite risk score. But we could show when comparing children within the different quartiles of PA that children in the lowest quartile of PA differed from the rest. This corroborates with studies only evaluating bone mass, finding that the benefits are gained with a 
Table 1 Descriptive data for age, anthropometrics, bone mineral content third lumbar vertebra (L3), bone size (area) third lumbar vertebra, bone quality (QUS) calcaneus, neuromuscular function, and knee muscle strength at baseline and the 2-year follow-up. Data are provided as means (SD)

\begin{tabular}{|c|c|c|c|c|c|c|c|c|}
\hline & \multicolumn{4}{|c|}{ Girls } & \multicolumn{4}{|c|}{ Boys } \\
\hline & \multicolumn{2}{|c|}{ Baseline } & \multicolumn{2}{|c|}{ Follow-up } & \multicolumn{2}{|c|}{ Baseline } & \multicolumn{2}{|c|}{ Follow-up } \\
\hline & $N$ & Value & $N$ & Value & $N$ & Value & $N$ & Value \\
\hline Age (years) & 119 & $7.8(0.6)$ & 108 & $9.7(0.6)$ & 150 & $7.9(0.6)$ & 138 & $9.9(0.6)$ \\
\hline \multicolumn{9}{|l|}{ Physical activity } \\
\hline Physical activity (hours/week) & 113 & $2.1(2.0)$ & 97 & $5.8(3.2)$ & 145 & $3.2(3.1)$ & 132 & $7.4(4.2)$ \\
\hline \multicolumn{9}{|l|}{ Anthropometry } \\
\hline Weight (kg) & 118 & $27.5(5.4)$ & 106 & $34.4(7.8)$ & 150 & $28.2(5.6)$ & 138 & $34.6(7.7)$ \\
\hline Height $(\mathrm{cm})$ & 118 & $128.8(6.6)$ & 106 & $139.9(7.8)$ & 150 & $129.6(6.5)$ & 138 & $140.7(7.0)$ \\
\hline Body mass index $\left(\mathrm{kg} / \mathrm{m}^{2}\right)$ & 118 & $16.5(2.4)$ & 106 & $17.4(3.0)$ & 150 & $16.6(2.3)$ & 138 & $17.4(2.9)$ \\
\hline \multicolumn{9}{|l|}{ Dual-energy X-ray absorptiometry (DXA) } \\
\hline Bone mineral content L3 (g) & 117 & $5.1(1.1)$ & 106 & $6.5(1.5)$ & 148 & $5.4(1.1)$ & 137 & $6.7(1.4)$ \\
\hline Bone area $\mathrm{L} 3\left(\mathrm{~cm}^{2}\right)$ & 117 & $7.2(1.0)$ & 106 & $8.4(1.2)$ & 149 & $7.7(1.0)$ & 137 & $8.8(1.1)$ \\
\hline \multicolumn{9}{|l|}{ Quantitative ultrasound (QUS) } \\
\hline $\begin{array}{l}\text { Broadband ultrasound } \\
\text { Attenuation }(\mathrm{dB} / \mathrm{MHz})\end{array}$ & 98 & $94.8(8.9)$ & 94 & $98.9(9.1)$ & 127 & $96.7(11.6)$ & 120 & $101.1(8.0)$ \\
\hline \multicolumn{9}{|l|}{ Neuromuscular function } \\
\hline Vertical jump height (cm) & 115 & $21.9(4.0)$ & 104 & $24.0(3.9)$ & 145 & $24.3(4.8)$ & 138 & $26.9(4.6)$ \\
\hline \multicolumn{9}{|l|}{ Muscle strength } \\
\hline Extension peak torque $180 \% \mathrm{~s}(\mathrm{Nm})$ & 118 & $34.1(7.6)$ & 105 & $48.7(10.8)$ & 149 & $36.1(8.6)$ & 136 & $51.6(11.8)$ \\
\hline
\end{tabular}

relative short duration or repetition of activities but that duration of PA are of less importance [33, 34]. At followup, the girls in the lowest quartile had a weekly duration of PA below $3 \mathrm{~h}$ and boys below $4.4 \mathrm{~h}$. This can be set in perspective of the $3.3 \mathrm{~h} /$ week of PE we exposed the POP intervention group to $[16,17,29]$, a duration that would lift most both girls and boys beyond in this study shown, unfavorable level of PA.

Study strengths include the population-based and prospective study design and the inclusion of multiple independent surrogate endpoint variables for fracture risk. A major limitation is the lack of information on nonorganized PA during leisure time, on participation rate, and on activity level during the PE classes. It would also have been advantageous with data on incident fractures to address if the composite score can identify fracture-prone individuals better than BMD alone. This is not possible to do in our study as the participants were too few in relation to the low fracture risk in these ages. It is thus not possible to state that the children in the lowest quartile of PA actually had more fractures than children within higher quartiles. It must also be confirmed in future studies that
Table 2 Correlation between duration of physical activity (PA) and Zscore for bone mineral content third lumbar vertebra (L3), bone size (area) third lumbar vertebra, bone quality (QUS) calcaneus, neuromuscular function, and knee muscle strength and the composite score (mean Z- score for BMC, bone size, bone quality, neuromuscular function, and muscle strength) for fractures. Correlation was done by Pearson correlation analyses after adjustment for age and height. Statistical significant differences are italicized

\begin{tabular}{|c|c|c|c|c|c|c|}
\hline & \multicolumn{3}{|c|}{ Baseline } & \multicolumn{3}{|c|}{ Follow-up } \\
\hline & $N$ & $r$ value & $p$ & $N$ & $r$ value & $p$ \\
\hline Bone mineral content L3 & 254 & 0.08 & 0.91 & 226 & 0.11 & 0.12 \\
\hline Bone area L3 & 255 & -0.01 & 0.87 & 226 & 0.12 & 0.09 \\
\hline Broadband ultrasound attenuation & 214 & 0.03 & 0.70 & 200 & 0.15 & 0.04 \\
\hline Vertical jump height & 249 & 0.09 & 0.20 & 225 & 0.12 & 0.12 \\
\hline Extension peak torque $180^{\circ} / \mathrm{s}$ & 256 & -0.01 & 0.93 & 224 & -0.01 & 0.91 \\
\hline Composite score & 257 & 0.05 & 0.49 & 227 & 0.18 & 0.01 \\
\hline
\end{tabular}


Table 3 Estimates for the Z-scores for bone mineral content third lumbar vertebra (L3), bone size (area) third lumbar vertebra, bone quality (QUS) calcaneus, neuromuscular function, and knee muscle strength and the composite score (mean Z-score for BMC, bone size, bone quality, neuromuscular function, and muscle strength) for fractures. A multilevel linear mixed model with unstructured covariance structure and fixed intercept only was used to examine the effect of PA on the composite score after adjustment for age and height. Statistical significant differences are italicized

\begin{tabular}{lllll}
\hline & $\beta$ & Std. error & $p$ & $95 \%$ Ci \\
\hline Bone mineral content L3 & 0.025 & 0.01 & 0.003 & $0.009,0.041$ \\
Bone area L3 & 0.021 & 0.01 & 0.032 & $0.002,0.040$ \\
Broadband ultrasound attenuation & 0.014 & 0.02 & 0.372 & $-0.016,0.044$ \\
Vertical jump height & 0.010 & 0.01 & 0.460 & $-0.016,0.035$ \\
Extension peak torque $180 \% \mathrm{~s}$ & 0.003 & 0.01 & 0.740 & $-0.015,0.022$ \\
Composite score & 0.014 & 0.01 & 0.05 & $0.000,0.028$ \\
\hline
\end{tabular}

the PA-induced benefits in the composite score remain into older ages. By use of mean Z-scores in the model, each factor is given equal importance for fracture risk reduction, which may be presumptuous. We can further not state if it is the low amount of PA that leads to the clustering effect or if children with low neuromuscular function and muscle strength are less physically active. The well-known difficulty to estimate PA in children [35] is another concern. However, objective measurements of PA, such as by accelerometer, are also criticized as these devices most often measure PA for few days, but represent the level of PA for a long period.

In summary, we conclude that low daily PA induce an unfavorable clustered risk factor score for fracture already at a young age and that high PA in the pre-pubertal period could induce a beneficial composite score as an estimation of fracture risk. Future prospective studies should evaluate if the effect of PA on the composite score remains in adulthood, and most important, if the composite score better predicts fractures than BMD alone.

Acknowledgments Financial support for this study was received from ALF, the Centre for Athletic Research, the Osterlund Foundation, the Kock Foundation, and the Region Skåne Foundation.

Compliance with ethical standards This study is approved by the Lund University Ethics Committee (LU 453-98, LU-368-99), registered as a clinical trial with registration identification ClinicalTrials.gov. NCT00633828, and carried out in accordance with the Declaration of Helsinki. Written informed consent was obtained from the parents or guardians of each child before study start.

\section{Conflicts of interest None.}

Open Access This article is distributed under the terms of the Creative Commons Attribution-NonCommercial 4.0 International License (http:// creativecommons.org/licenses/by-nc/4.0/), which permits any noncommercial use, distribution, and reproduction in any medium, provided you give appropriate credit to the original author(s) and the source, provide a link to the Creative Commons license, and indicate if changes were made.

\section{References}

1. Seeman E (2003) Invited review: pathogenesis of osteoporosis. J Appl Physiol 95(5):2142-2151. https://doi.org/10.1152/ japplphysiol.00564.2003

2. Heaney RP, Abrams S, Dawson-Hughes B, Looker A, Looker A, Marcus R, Matkovic V, Weaver C (2000) Peak bone ass. Osteoporos Int 11(12):985-1009. https://doi.org/10.1007/ s001980070020

3. Qaseem A, Snow V, Shekelle P, Hopkins R Jr, Forciea MA, Owens DK, Clinical Efficacy Assessment Subcommittee of the American College of P (2008) Pharmacologic treatment of low bone density or osteoporosis to prevent fractures: a clinical practice guideline from the American College of Physicians. Ann Intern Med 149(6):404-415

4. Kohrt WM, Bloomfield SA, Little KD, Nelson ME, Yingling VR (2004) Physical activity and bone health. Med Sci Sports Exerc 36(11):1985-1996

5. Gunter KB, Almstedt HC, Janz KF (2012) Physical activity in childhood may be the key to optimizing lifespan skeletal health. Exerc Sport Sci Rev 40(1):13-21. https://doi.org/10.1097/JES. 0b013e318236e5ee

6. McNamara A, Gunter K (2012) The influence of participation in Better Bones and Balance ${ }^{\mathrm{TM}}$ on skeletal health: evaluation of a community-based exercise program to reduce fall and fracture risk. Osteoporos Int 23(6):1813-1822. https://doi.org/10.1007/s00198011-1816-6

7. Nordström A, Olsson T, Nordström P (2005) Bone gained from physical activity and lost through detraining: a longitudinal study in young males. Osteoporos Int 16(7):835-841. https://doi.org/10. 1007/s00198-004-1749-4

8. Tveit M, Rosengren BE, Nilsson J-Å, Ahlborg HG, Karlsson MK (2013) Bone mass following physical activity in young years: a mean 39-year prospective controlled study in men. Osteoporos Int 24(4):1389-1397. https://doi.org/10.1007/s00198-012-2081-z

9. Tveit M, Rosengren BE, Nyquist F, Nilsson J-Å, Karlsson MK (2013) Former male elite athletes have lower incidence of fragility fractures than expected. Med Sci Sports Exerc 45(3):405-410. https://doi.org/10.1249/MSS.0b013e318274fdf3

10. Bass SL, Saxon L, Daly RM, Turner CH, Robling AG, Seeman E, Stuckey S (2002) The effect of mechanical loading on the size and shape of bone in pre-, peri-, and postpubertal girls: a study in tennis players. J Bone Miner Res 17(12):2274-2280. https://doi.org/10. 1359/jbmr.2002.17.12.2274

11. Cöster ME, Rosengren BE, Karlsson C, Dencker M, Karlsson MK Effects of an 8-year childhood physical activity intervention on 
musculoskeletal gains and fracture risk. Bone 93:139-145. https:// doi.org/10.1016/j.bone.2016.09.021

12. Duan Y, Parfitt AM, Seeman E (1999) Vertebral bone mass, size, and volumetric density in women with spinal fractures. J Bone Miner Res 14(10):1796-1802. https://doi.org/10.1359/jbmr.1999. 14.10.1796

13. Hind K, Burrows M (2007) Weight-bearing exercise and bone mineral accrual in children and adolescents: a review of controlled trials. Bone 40 (1):14-27. doi:https://doi.org/10.1016/j.bone.2006. 07.006

14. Kannus P, Haapasalo H, Sankelo M, Sievanen H, Pasanen M, Heinonen A, Oja P, Vuori I (1995) Effect of starting age of physical activity on bone mass in the dominant arm of tennis and squash players. Ann Intern Med 123(1):27-31

15. McKay HA, Petit MA, Schutz RW, Prior JC, Barr SI, Khan KM (2000) Augmented trochanteric bone mineral density after modified physical education classes: a randomized school-based exercise intervention study in prepubescent and early pubescent children. J Pediatr 136 (2):156-162. doi:https://doi.org/10.1016/S00223476(00)70095-3

16. Valdimarsson Ö, Linden C, Johnell O, Gardsell P, Karlsson MK (2006) Daily physical education in the school curriculum in prepubertal girls during 1 year is followed by an increase in bone mineral accrual and bone width - data from the prospective controlled Malmö pediatric osteoporosis prevention study. Calcif Tissue Int 78 (2):65-71. doi:https://doi.org/10.1007/s00223-005-0096-6

17. Daly RM, Ducher G, Hill B, Telford RM, Eser P, Naughton G, Seibel MJ, Telford RD (2016) Effects of a specialist-led, school physical education program on bone mass, structure, and strength in primary school children: a 4-year cluster randomized controlled trial. J Bone Miner Res 31(2):289-298. https://doi.org/10.1002/ jbmr.2688

18. Lord SR, Ward JA, Williams P, Strudwick M (1995) The effect of a 12-month exercise trial on balance, strength, and falls in older women: a randomized controlled trial. J Am Geriatr Soc 43(11):11981206. https://doi.org/10.1111/j.1532-5415.1995.tb07394.x

19. Rosengren BE, Ribom EL, Nilsson J-Å, Mallmin H, Ljunggren Ö, Ohlsson C, Mellström D, Lorentzon M, Stefanick M, Lapidus J, Leung PC, Kwok A, Barrett-Connor E, Orwoll E, Karlsson MK (2012) Inferior physical performance test results of 10,998 men in the MrOS Study is associated with high fracture risk. Age Ageing 41(3):339-344. https://doi.org/10.1093/ageing/afs010

20. Cöster ME, Fritz J, Nilsson J-Å, Rosengren BE, Dencker M, Karlsson MK (2017) How does a physical activity programme in elementary school affect fracture risk? A prospective controlled intervention study in Malmo, Sweden. BMJ open 7(2):e012513. https://doi.org/10.1136/bmjopen-2016-012513

21. Fritz J, Cöster ME, Nilsson J-Å, Rosengren BE, Dencker M, Karlsson MK (2016) The associations of physical activity with fracture risk - a 7-year prospective controlled intervention study in 3534 children. Osteoporos Int 27(3):915-922. https://doi.org/ 10.1007/s00198-015-3311-y

22. Andersen LB, Harro M, Sardinha LB, Froberg K, Ekelund U, Brage S, Anderssen SA Physical activity and clustered cardiovascular risk in children: a cross-sectional study (The European Youth Heart
Study). The Lancet 368(9532):299-304. https://doi.org/10.1016/ S0140-6736(06)69075-2

23. Andersen LB, Wedderkopp N, Hansen HS, Cooper AR, Froberg K (2003) Biological cardiovascular risk factors cluster in Danish children and adolescents: the European Youth Heart Study. Prev Med 37(4):363-367. https://doi.org/10.1016/S0091-7435(03)00145-2

24. Berenson GS, Srinivasan SR, Bao W, Newman WP 3rd, Tracy RE, Wattigney WA (1998) Association between multiple cardiovascular risk factors and atherosclerosis in children and young adults. The Bogalusa Heart Study. N Engl J Med 338(23):1650-1656. https:// doi.org/10.1056/NEJM199806043382302

25. D'Agostino RB, Vasan RS, Pencina MJ, Wolf PA, Cobain M, Massaro JM, Kannel WB (2008) General cardiovascular risk profile for use in primary care. The Framingham Heart Study 117(6): 743-753. https://doi.org/10.1161/circulationaha.107.699579

26. Hurtig-Wennlöf A, Ruiz JR, Harro M, Sjöström M (2007) Cardiorespiratory fitness relates more strongly than physical activity to cardiovascular disease risk factors in healthy children and adolescents: the European Youth Heart Study. Eur J Cardiovasc Prev Rehabil 14(4):575-581. https://doi.org/10.1097/HJR. 0b013e32808c67e3

27. Kanis JA, Hans D, Cooper C, Baim S, Bilezikian JP, Binkley N, Cauley JA, Compston JE, Dawson-Hughes B, El-Hajj Fuleihan G, Johansson H, Leslie WD, Lewiecki EM, Luckey M, Oden A, Papapoulos SE, Poiana C, Rizzoli R, Wahl DA, McCloskey EV (2011) Interpretation and use of FRAX in clinical practice. Osteoporos Int 22(9):2395. https://doi.org/10.1007/s00198-011$1713-\mathrm{Z}$

28. Stenevi-Lundgren S, Daly RM, Karlsson MK (2010) A schoolbased exercise intervention program increases muscle strength in prepubertal boys. Int J Pediatr 2010:9. https://doi.org/10.1155/ 2010/307063

29. Stenevi-Lundgren S, Daly RM, Lindén C, Gärdsell P, Karlsson MK (2009) Effects of a daily school based physical activity intervention program on muscle development in prepubertal girls. Eur J Appl Physiol 105(4):533-541. https://doi.org/10.1007/s00421-0080932-2

30. Duke PM, Litt IF, Gross RT (1980) Adolescents' self-assessment of sexual maturation. Pediatrics 66(6):918-920

31. Kaufman JJ, Einhorn TA (1993) Perspectives: ultrasound assessment of bone. J Bone Miner Res 8(5):517-525. https://doi.org/10. 1002/jbmr.5650080502

32. Melton LJ, Atkinson EJ, O'Fallon WM, Wahner HW, Riggs BL (1993) Long-term fracture prediction by bone mineral assessed at different skeletal sites. J Bone Miner Res 8(10):1227-1233. https:// doi.org/10.1002/jbmr.5650081010

33. Karlsson MK, Magnusson H, Karlsson C, Seeman E (2001) The duration of exercise as a regulator of bone mass. Bone 28(1):128 132. https://doi.org/10.1016/S8756-3282(00)00405-1

34. Lanyon LE (1992) The success and failure of the adaptive response to functional load-bearing in averting bone fracture. Bone 13:S17S21

35. Welk GJ, Corbin CB, Dale D (2000) Measurement issues in the assessment of physical activity in children. Res Q Exerc Sport 71(sup2):59-73. https://doi.org/10.1080/02701367.2000. 11082788 